\title{
A Stochastic Programming Approach to Supply Chain Disruptions Planning and Management
}

\author{
S. M. Ali and K. Nakade
}

\begin{abstract}
In this paper, we propose a stochastic programming approach to manage supply chain disruptions of an enterprise with an emphasis on demand and disruptions uncertainty. The supply chain considered here is multi-product, multi-agent in nature. However, the model considers purchasing cost, inventory cost and emergency ordering cost. Decisions such as ordering quantities in pre-disruptions and post-disruptions situation are taken into consideration. On the other hand, quality and delivery performance requirements are also included in the proposed analytical framework. We use Monte Carlo sampling approach for the purpose of sampling for a given probability distribution of stochastic parameters. In addition, we consider a disruptions planning case study and apply Benders decomposition (BD)/L-shaped algorithm to solve the model. The model is coded on GAMS 24.1.3 and run by CPLEX (12.5.1.0) and DECIS solver. We minimize total cost that includes first stage cost and second stage disruptions scenario cost. Several test instances with different disruptions scenarios are considered. We then compare the total costs under several disruptions scenarios. We hope that the model could be used as an effective tool to analyze and decide on supply chain disruptions planning and management of an enterprise thus it could contribute in continuity of manufacturing/business operations and therefore help in building a resilient supply chain.
\end{abstract}

Index Terms-Stochastic programming, supply chain disruptions, benders decomposition, Monte Carlo simulation.

\section{INTRODUCTION}

Rapid globalization has introduced immense supply chain disruptions risk on the agents of a corporate supply chain with devastating impacts in an interconnected and interrelated nature. Some recent examples include earthquakes, tsunami, economic crises, supplier bankruptcy, SARS, strikes, terrorist attacks, etc. that have been imposing threat on market share and enterprise existence. Hendricks and Singhal reports that supply chain disruptions have long term negative effects on the supply chain financial performance. For example, some companies suffer $33-40 \%$ lower stock returns than expected as a result of disruption [1]. Traditional supply chain can perform well under a disruptions free environment. But, disruptions to supply chain are almost inevitable in today's complex dynamic settings with prevailing time sensitive turbulent business environment. In the real world, disruptions do occur and the best business plans are those that anticipate and prepare for this inevitability, in particular in dealing with foreign suppliers [2]. Thus, the researchers in the area of

Manuscript received November 5, 2013; revised February 13, 2014.

The authors are with the Department of Architecture, Civil Engineering and Industrial Management Engineering in Nagoya Institute of Technology, Nagoya, Japan (e-mail: syed.mithun@gmail.com,nakade@nitech.ac.jp). supply chain risk management in recent years are motivated to explore the response mechanisms while a disruption takes place in any components of a supply chain. Despite the importance of disruptions management to sustain the competitive edge, little research [1], [3] has been conducted in the important area of supply chain disruptions and their impacts [4] so far.

In the literature, the promising concept of supply chain disruption has been originated as a branch of supply chain risk management. For instance, Tang divides supply chain risks into two categories: operational risk and disruption risk [5]. In addition, Chopra and Sodhi [6] classify supply chain risks into nine parts: 1) disruptions 2) delays 3) systems 4) forecasts 5) intellectual property 6) procurement 7) receivables 8) inventory and 9) capacity. Two common modes of disruptions are supply and demand disruptions. Therefore, to mitigate negative impacts of disruptions on market or on supply chain, enterprise could adopt proactive planning by following and implementing some approach such as scenario based decision making/scenario based planning/scenario based strategy formulation, etc. Despite the ever increasing importance [7]-[9] of supply chain disruptions management, there has been little application of quantitative modeling techniques to the topic thus far; in general, most of the papers simply provide qualitative insights into the problem [10]. We apply quantitative insights to disruptions management and model demand and disruptions uncertainty on a common platform. However, we implement supply disruptions in the same model by treating it in a different way.

Most recently, many a number of researchers start to model supply disruptions or demand disruptions by adopting quantitative approach thus seeking more realistic way to mitigate, recover from and cope with disruptions successfully. Actually, recent high profile catastrophic events such as Japan tsunami 2011, the hurricane Katrina and Rita in 2005, the tsunami in 2004, terrorist attack $9 / 11$, etc. have motivated researchers to include supply chain disruptions risk into procurement and supply chain[5], [6], [11]-[17]. Other types of catastrophic events that can interrupt business operations are snowstorms, heavy rain, excessive wind, fire, industrial and road accidents, strikes, and changes in government regulations [18], [19]. Thus, the possibility of supply disruptions should be considered during decision making. Some authors suggest dual and/or multiple sourcing as one of the efficient strategies to mitigate supply chain disruption risk [16], [20]-[32]. Though multiple sourcing strategy is more reliable, it adds additional cost for negotiation, making contract and monitoring the quality [33], et al.

A very well-known and widely cited example that highlights supply disruption and effectiveness of dual 
sourcing strategy is the case of Nokia-Ericsson in 2000. The Philip`s microchips plant was shut down due to a fire accident. It caused Ericsson loss for about $\$ 400$ million, while Nokia managed to source from alternative suppliers thus minimized the disruption effect [34]. One recent large scale disaster that disrupted supply chain globally and forces the decision maker to think about supply chain disruptions is the Japan earthquake and tsunami in 2011. The earthquake and tsunami in japan affected the supply chain of different organizations both domestically and internationally. During the 1960s and 1970s, Japan rose up as the world's second largest manufacturer. It then became one of the major manufacturing hubs in the world. For instance, Japan provides $60 \%$ of the world silicon used for production of semiconductor chip. Besides, Japan is the world's leading supplier of dynamic random access memory and flash memory. Flash memory is used in standard logic controllers (SLC), liquid crystal display (LCD), and LCD parts and materials. After the catastrophic disaster, the prices of the components soared by $20 \%$, showing the global supply chain dependency on Japan [35]. These examples show the importance of having multiple suppliers to cope with supply disruptions.

Despite the fact that demand disruptions happen infrequently, it carries significant impact on supply chain [5]. In 2008, many firms around the globe experience large scale demand disruptions due to the global financial crisis. For instance, nearly 1000 toy manufacturers are shut down in Southern China in 2008 because of the sudden order cancellation from U.S and Europe. Chen and Zhang [36] examine the effects of demand disruptions on production control and supplier selection problem. They consider a three-echelon supply chain system and model the customer demand as a jump-diffusion process. Besides, several researches are conducted in order to implement a coordination mechanism when a demand disruption occurs. For example, Dong and Ming [37] establishes coordination mechanisms for a one-supplier-one-retailer supply chain that experiences demand and price factor disruptions at the same time in the planning horizon. In addition, Xiao, Qi and Yu [38] investigate the coordination mechanism for a supply chain with one manufacturer and two competing retailers. They consider different deterministic demand disruptions scenario and build quantity discount policy.

The above discussion makes an image on the research in the area of disruptions management in a state-of-the art environment. In view of this, the significance of disruptions planning can't be overlooked in present supply chain and disruptions management domain. Thus, we apply stochastic programming approach and integrate demand and disruptions uncertainty that could naturally present in a supply chain. However, supply disruptions are also captured in this framework. In addition, the model includes quality aspects of products and delivery performance of suppliers. The model could be adopted by the decision maker for making decision in an uncertain environment arising due to disruptions.

The rest of the paper is structured as follows. Section II discusses the importance of modeling and decision making under uncertainty. Section III addresses the problem statement. Section IV presents the analytical framework.
Section V deals with related computational experiments. Finally, Section VI concludes the paper.

\section{MODELING AND DECISION MAKING UNDER UNCERTAINTY}

In a global economy, the key to success greatly depends largely on effectively incorporating uncertainty in supply chain planning and decision making process. Considering the drawbacks of deterministic models in business success and continuity management in the present supply chain domain; recently, researchers, academia and real world participants are encouraged to include uncertainty in supply chain coordination and planning in practice. One important consideration for the insertion of uncertainty in supply chain planning is the mode of representing stochastic or uncertain parameters. Two modes are described in the literature. These are scenario-based approach and distribution-based approach In the former approach, a random parameter is presented by a set of discrete scenarios. These scenario sets describe all its possible future outcomes. Thus, scenario-based approach captures uncertainty by representing it in terms of number of discrete realizations of the stochastic terms hence constituting distinct scenarios. The major challenge and difficulty arise in this method is its computational complexity. To overcome the computational burden, continuous probability distributions for the random parameters are often used [39]. It reduces the problem size at the expense of imposing non-linearity into the problem. However, an effective algorithm for example Dantzig-Wolfe Decomposition algorithm [40] or Benders decomposition [41], also known as L-shaped method of Slyke and Wets [42], may be applied to effectively solve large scale scenario based stochastic programming. One of the most popular and widely used techniques for planning under uncertainty is two-stage stochastic programming [43]. In this approach, the decision variables are classified into two sets. The variables which are made prior to resolution of uncertainty are termed as first-stage variables or design variables ('here-and-now' decisions). Based on here-and-now decisions and the realization of the random events, the second stage or control variables are made to optimize in an uncertain environment. This is termed as 'wait-and-see decision' and reflects the way a decision maker adapts/responses to the unfolding uncertainty. The uncertainty is expressed as a stochastic nature of the costs related to second stage variable. Therefore, the objective function consists of the sum of first stage cost and the expected value of the second stage cost. It is pointed here that we apply Benders Decomposition/L-shaped algorithm to solve the proposed model. In the next section, we describe the problem statement we want to explore.

\section{PROBLEM STATEMENT}

This paper studies a supply chain consisting of multiple agents-outside suppliers, local supplier and distributors. A set of products are outsourced from a local supplier as well as from a set of outside suppliers. These products are then distributed to the customers through a given supply chain via different distribution centers/depots/warehouses located at 
different regions in a territory. The customer demands vary depending on the type of products and locations. However, from our experience we see that customers might experience different levels of product demand based on disruptions signals or after the occurrence of a disruptions in practice. For instance, customers want to buy more petroleum oil when they hear about Middle East instability. On the other hand, suppliers also experience disruptions and its devastating impacts in the stages of their production process/sourcing process. In order to effectively face disruptions and its associated effect in an uncertain environment, dual or multiple sourcing is an option which is more or less discussed in the supply chain risk management literature. The effectiveness and applicability of dual/multiple sourcing are discussed in the introduction section. In our work, the distributor has a fixed and reliable local supplier having limited capacity. It is assumed that the local supplier has no disruption effect. Therefore, the local supplier acts as a backup supplier to mitigate disruption effect, at the expense of additional cost though. The management selects two or more outside suppliers thus adopting multiple sourcing strategies from the set of available suppliers. Thus, a tradeoff exists among initial order allocation among the suppliers before disruptions and emergency order to local supplier and the related costs in respect of a disruptions scenario.

It is worth mentioning that one of the most important considerations in any outsourcing decision is the quality of the incoming products as well as receiving the ordered products on time. Because, company reputation and brand image greatly depend on quality and delivery performance. Keeping in view these aspects, several authors [44]-[47] describe the importance of considering quality and delivery aspects, when it comes to outsourcing.

In this paper, a two-stage stochastic programming approach is proposed for a multi-product multi-agent supply chain within a disruption planning framework that takes into account the purchasing cost, inventory holding costs and emergency ordering cost. Hence, this model reflects a tradeoff analysis among ordering quantities in a pre-disruption and post-disruption situation and the related costs. However, to include quality and delivery performance, we include constraints (4) and (5) as hard constraints in the proposed model. Note that right-hand-sides of the quality and delivery constraints can be modified to find alternative solutions. As response policies/strategies to cope with disruptions, the formulation tries to evaluate order quantities in normal and disrupted state at different distribution center under different disruptions scenario.

In the stochastic programming model, the decision variables are separated into first stage (Here-and-now) and second stage (wait-and-see) decisions. The first stage decisions are initial order placed with the outside supplier and initial order to the local supplier whereas the second stage decisions are the emergency order quantities. After the initial order, first level of uncertainty is resolved when the disruptions scenario happens. Due to disruptions to the outside supplier, his capacity is reduced thus some fraction of the initial order could be supplied by the main supplier, while local supplier supplies whatever order placed by the decision maker. When the uncertainties related to disruptions and demands are revealed, the decision maker calls for emergency order at a higher cost.

The proposed stochastic programming formulation minimizes the total expected cost that includes the first stage cost and the expected second stage cost or scenario cost. The first stage cost comprises of purchasing cost from local supplier. The second stage costs expresses the costs related to disruptions scenario. We include purchasing cost, inventory holding cost and emergency ordering cost to model the scenario cost. We consider single period model and assume average inventory cost. Since the scenarios follow discrete distribution, the expected second stage cost is equal to the product of the scenario probability, $\mathrm{P}_{\mathrm{s}}$ and the associated costs summed over all the scenarios, $\mathrm{S}$.

In sum, the objective of the proposed stochastic framework is to minimize total cost of a multi-agent multiproduct supply chain by considering decisions such as: (1) optimal ordering policies to the available set of suppliers (3) maximizing the quality of items received from the suppliers, and (4) minimizing the late deliveries from the outside suppliers.

In the next section, the proposed mathematical model is presented.

\section{MODEL FORMULATION}

In the first step, we identify the index sets, parameters and decision variables in order to make an attempt to develop a quantitative disruption management framework. The index sets are defined below. And, the decision variables are provided in Table I.

Sets Descriptions

I Set of outside suppliers

$J \quad$ Set of items

$L \quad$ Set of distribution center

$S \quad$ Set of disruptions scenarios

TABLE I: DECISION VARIABLES IN THE MODEL

\begin{tabular}{cl}
\hline $\begin{array}{c}\text { Decision } \\
\text { Variables }\end{array}$ & Descriptions \\
\hline$x_{i j l}$ & $\begin{array}{l}\text { Amount of item j ordered from supplier i at distribution } \\
\text { center } 1, i \in I, j \in J \text { and } l \in L\end{array}$ \\
$Q_{j l}^{l o c}$ & $\begin{array}{l}\text { Amount of item j ordered from local supplier at } \\
\text { distribution center } 1, j \in J \text { and } l \in L\end{array}$ \\
$Q_{j l s}^{\text {eme }}$ & Emergency order placed for item j at distribution center 1 \\
& under disruption scenario s. $j \in J, l \in L$ and $s \in S$ \\
$I_{j l s}$ & Inventory level of product type j in distribution center l \\
& under scenario s, $j \in J, l \in L$, and $s \in S$ \\
\hline \hline
\end{tabular}

The parameters used in the model are provided in Table II. In the next, the constraints of the proposed model are given in subsection 3.1., the analytical framework is presented in subsection 3.2.

\section{A. Constraints in the Proposed Model}

The model considers six types of constraints. They are inventory constraints related to distribution center, and emergency order constraints, quality and delivery performance constraints of the suppliers, and finally the supplier capacity constraint. These constraints are illustrated below: 
TABLE II: THE PARAMETERS IN THE PROPOSED MATHEMATICAL MODEL

\begin{tabular}{|c|c|}
\hline Parameters & Descriptions \\
\hline$P_{s}$ & Probability of disruptions scenario s, $s \in S$ \\
\hline$D_{j l s}$ & $\begin{array}{l}\text { Demand of item } \mathrm{j} \text { in distribution center } 1 \text { in disruption } \\
\text { scenario s } j \in J, l \in L \text { and } s \in S\end{array}$ \\
\hline$H_{j l}$ & $\begin{array}{l}\text { Unit inventory cost of product type } \mathrm{j} \text { in distribution center } \\
1, j \in J, l \in L\end{array}$ \\
\hline$I N V_{j l s}^{\max }$ & $\begin{array}{l}\text { Inventory limit at a distribution center for a product type } \\
\text { in a scenario, } j \in J, l \in L \text { and } s \in S\end{array}$ \\
\hline$c_{i j l}$ & $\begin{array}{l}\text { Unit cost (in } \$ / \text { unit) of item } \mathrm{j} \text { quoted by supplier i to } \\
\text { distribution center } 1, i \in I, j \in J \text { and } l \in L\end{array}$ \\
\hline$C_{j l}^{l o c}$ & $\begin{array}{l}\text { Unit cost (in } \$ / \text { unit) of item } \mathrm{j} \text { quoted by fixed local } \\
\text { supplier to distribution center } 1 \text { in normal } \\
\text { condition, } j \in J \text { and } l \in L\end{array}$ \\
\hline$C_{j l}^{e m e}$ & $\begin{array}{l}\text { Emergency cost per unit (in } \$ / \text { unit) to be added to unit } \\
\text { cost quoted by local supplier in normal condition, } \\
j \in J \text { and } l \in L\end{array}$ \\
\hline$Q_{j l}^{\min l o c}$ & $\begin{array}{l}\text { Minimum order to local supplier for a product type } \mathrm{j} \text { at a } \\
\text { distribution center, } 1 \text { in normal condition } \\
j \in J \text { and } l \in L\end{array}$ \\
\hline$Q_{j l s}^{\max l o c}$ & $\begin{array}{l}\text { Maximum order to local supplier for a product type } \mathrm{j} \text { at a } \\
\text { distribution center } 1 \text { under scenario, s } \\
j \in J, l \in L \text { and } s \in S\end{array}$ \\
\hline$F_{i s l}$ & $\begin{array}{l}\text { Percentage of order supplied by the outside supplier i in } \\
\text { disruption scenario s to distribution center } \\
1, i \in I, S \in S \text { and } l \in L\end{array}$ \\
\hline$q_{i j}$ & $\begin{array}{l}\text { Fraction of poor quality items of type } \mathrm{j} \text { from supplier } \mathrm{i} \text {, } \\
i \in I, j \in J\end{array}$ \\
\hline$q_{j}^{l o c}$ & $\begin{array}{l}\text { Fraction of poor quality items of type } \mathrm{j} \text { from local supplier, } \\
j \in J\end{array}$ \\
\hline$t_{i j}$ & $\begin{array}{l}\text { Fraction of late items of type } \mathrm{j} \text { from supplier } \mathrm{i} \\
i \in I, j \in J\end{array}$ \\
\hline$\tau_{j}$ & Pre-set quality tolerance factor for product type $\mathrm{j}, j \in J$ \\
\hline$\tau_{d}$ & $\begin{array}{l}\text { Pre-set delivery tolerance factor expressed as percentage } \\
\text { of demand }\end{array}$ \\
\hline
\end{tabular}

\section{1) Inventory constraints}

The inventory of product $i$ at distribution center $l$ in a scenario, $\mathrm{s}$ is equal to the product received from local supplier plus incoming flows from outside supplier. It is worth mentioning that due to the impacts of disruptions on the outside supplier, they could not supply the whole amount, $x_{i j l}$ as was previously ordered before disruptions took place. Hence, the effect of disruptions is taken by the factor, $F_{i s l}$ which varies depending on the type and extent of disruptions. However, it also varies depending on the location of the distribution centers and distance of the same from the outside suppliers. Because, mode of transportation and the goods carried are also affected by disruptions.

$$
I_{j l s}=Q_{j l}^{l o c}+\sum_{i \in I} F_{i s l} x_{i j l}, \quad \forall j \in J, l \in L, s \in S
$$

The inventories are limited by their corresponding upper bound. This upper bound is determined based on demand of a particular product in a particular location under a scenario, $s$ while considering the distribution center capacities to store particular types of products.

$$
I_{j l s} \leq I N V_{j l s}^{\max }, \quad \forall j \in J, l \in L, s \in S
$$

\section{2) Emergency order constraints}

The enterprise asks for emergency order when there is shortage of inventory to meet the demand and is determined by the following equation after calculating inventory in a disruption scenario.

$$
Q_{j l s}^{e m e} \geq D_{j l s}-I_{j l s} \quad \forall j \in J, l \in L, s \in S
$$

\section{3) Quality and delivery performance constraints}

The following constraints fulfill the requirements for high quality and on-time delivery of the received items from the suppliers. Since, the requirements for high quality and on-time delivery of the received items are generally expressed as a percentage of demand in real world business practices; we can express the required quality performance as

$$
\begin{gathered}
\sum_{i \in I} q_{i j} \sum_{s \in S} F_{i s l} x_{i j l}+q_{j}^{l o c} Q_{j l}^{l o c}+q_{j}^{l o c} \sum_{s \in S} Q_{j l s}^{e m e} \leq \tau_{j} \sum_{s \in S} D_{j l s}, \\
\forall j \in J, l \in L
\end{gathered}
$$

Here, $\tau_{j}$ is the quality tolerance factor for specific product type received at the distribution center and expressed as percentage of demand.

However, the delivery performance can be expressed as $\sum_{i \in I} t_{i j} \sum_{s \in S} F_{i s l} x_{i j l} \leq \tau_{d} \sum_{s \in S} D_{j l s}, \quad \forall j \in J, l \in L$ Here, $\tau_{d^{\prime}}$ is the pre-set delivery tolerance factor expressed as a percentage of demand.

\section{4) Supplier capacity constraints}

We assume that outside supplier has infinite capacity. On the contrary, the ordered quantities to local supplier in normal $\left(Q_{j l}^{l o c}\right)$ and emergency ( $\left.Q_{j l s}^{e m e}\right)$ situation are restricted by the following constraints respectively.

$$
\begin{gathered}
Q_{j l}^{l o c} \geq Q_{j l}^{\min l o c}, \forall j \in J, l \in L \\
Q_{j l s}^{e m e} \leq Q_{j l s}^{\max l o c}, \forall j \in J, l \in L, s \in S
\end{gathered}
$$

\section{B. Proposed Model}

Our model is based on some assumptions given below.

1) Local supplier is not subject to disruptions whereas outside suppliers are prone to disruptions. Therefore, outside supplier can't supply the exact amount as was previously ordered.

2) The model assumes a single period.

On the basis of the above mentioned assumptions and the constraints along with defined variables and parameter, the analytical framework is formulated as

$$
\begin{gathered}
\operatorname{Min} Z=\sum_{j \in J} \sum_{l \in L} Q_{j l}^{l o c} C_{j l}^{l o c} \\
+\sum_{s} p_{s}\left\{\begin{array}{l}
\left.\sum_{i \in l} \sum_{j \in J} \sum_{l \in L} F_{i s l} x_{i j l} c_{i j l}+\sum_{j \in J} \sum_{l \in L} \frac{1}{2} H_{j l} I_{j l s}\right\} \\
+\sum_{j \in J} \sum_{l \in L}\left(C_{j l}^{e m e}+C_{j l}^{l o c}\right) Q_{j l s}^{e m e}
\end{array}\right\} \\
I_{j l s}=Q_{j l}^{l o c}+\sum_{i \in I} F_{i s l} x_{i j l,} \\
\forall j \in J, l \in L, S \in S
\end{gathered}
$$

$$
\begin{aligned}
& \sum_{i \in I} q_{i j} \sum_{s \in S} F_{i s l} x_{i j l}+q_{j}^{l o c} Q_{j l}^{l o c} \\
& +q_{j}^{l o c} \sum_{s \in S} Q_{j l s}^{e m e} \leq \tau_{j} \sum_{s \in S} D_{j l s,} \quad \forall j \in J, l \in L
\end{aligned}
$$




$$
\begin{gathered}
\sum_{i \in I} t_{i j} \sum_{s \in S} F_{i s l} x_{i j l} \leq \tau_{d} \sum_{s \in S} D_{j l s}, \quad \forall j \in J, l \in L \\
I_{j l s} \leq I N V_{j l s,}^{\max } \forall j \in J, l \in L, s \in S \\
Q_{j l s}^{\text {eme }} \leq Q_{j l s,}^{\max l o c} \forall j \in J, l \in L, s \in S \\
Q_{j l}^{l o c} \geq Q_{j l,}^{\min l o c} \quad \forall j \in J, l \in L \\
x_{i j l}, Q_{j l}^{l o c}, Q_{j l s}^{e m e}, I_{j l s} \geq 0, \forall i \in I, j \in J, l \in L, s \in S
\end{gathered}
$$

The objective function (1) minimizes the expected cost which is the summation of first stage cost and the second stage expected cost/scenario cost. Herein, Scenario-based disruption effect is considered by taking the probability of each scenario. Eq. (2) determines the inventory level of each product in a disruption scenario at each distribution center. Eq (3) establishes the emergency order in response to disruption. Eq. (4)-(5) imposes quality and delivery performance requirements of outside supplier. Firm`s inventory limit for each item at each distribution center is enforced through Eq. (6). Eq. (7)-(8) limits the ordering quantity to local supplier. Finally, (9) is non-negativity constraints associated with decision variables considered.

\section{COMPUtational EXPERIENCE}

In this section, numerical experiments are designed and implemented to demonstrate the effectiveness and applicability of the proposed model in practice. Let us consider a simplified representation of a supply chain consisting of two outside suppliers, one local supplier and two distributors. Additionally, the distributors outsource two categories of product from the three suppliers. We design and execute 10 test instances in order to show the performance of the model. With a view to examining the effect of disruptions scenario on total cost, we consider several disruptions scenarios. We commence the experiment with 2 scenarios and continue up to 11 scenarios, with each having the same probability of occurrence. In the analysis, we consider normal probability distribution for product demand and order fraction realization. We generate discrete values and use those in the model. Other parameters such as costs and quality/delivery tolerance factors are assumed in this hypothetical case study. Table III summarizes the range of data of the test problems we solved. We don`t show all data values for reasons of clarity and comprehensibility, rather we show the range.

TABLE III: RANGE OF DATA FOR THE TEST PROBLEMS

\begin{tabular}{ll}
\hline \hline Parameters & Range of data \\
\hline Product Demand & $D \approx N(1500,500)$ \\
Fraction of order/ outside & $F \approx N(0.80,0.1)$ \\
Purchasing cost/outside $(\$)$ & {$[7,9]$} \\
Purchasing cost/local $(\$)$ & {$[10,13]$} \\
Inventory cost $(\$)$ & {$[1,2]$} \\
Emergency cost $(\$)$ & {$[12,14]$} \\
Quality tolerance factor & {$[0.02,0.04]$} \\
Delivery tolerance factor & {$[0.02,0.04]$} \\
Ordering limit/local & {$[600,50000]$} \\
Inventory Limit & {$[20,000]^{*}$} \\
we assign same inventory limit for all the trials.
\end{tabular}

However, our model can accommodate different inventory limits that a decision maker might be interested to fix for the particular product-depot-scenario combinations.

We assume some fixed values for the tolerance factors in our analysis. We state here that the quality and tolerance factor can be changed depending on the disruption scenario or organizational context and the model will thus produce different results. We consider different number of scenarios for the test instances as shown in Table IV. For the sake of simplicity of analysis we assume same probability of occurrence of each of the scenarios considered in every test case. To make the model more realistic, data related to disruption probabilities, the Product demand and the fraction of order supplied by the outside suppliers for any products type could be achieved from the historical information of demand/supplier disruptions database of an enterprise. From those benchmark values, we could generate random values by assuming normal distribution for instance. In fact, many real world events could be described by normal distribution as it offers the characteristics of holding natural variation that really persist in a natural environment. As such, normality assumption is widely invoked in the literature [48].

The model presented above is implemented under GAMS modeling language and solved by DECIS solver. The DECIS solver works on the basis of probability information supplied in the GAMS input file. DECIS solver can't deal with continuous distribution. It only works when it gets discrete data with associated probability. Hence, probability assignment is required to the data values. Here, at first we assume demand and percentage of order realized as normally distributed random variable having properties of $D \approx N(1500,500)$ and $F \approx N(0.80,0.1)$ respectively. And, from the large samples $(100,000)$ generated for each of the parameter, we put demand and order fraction realization values by scenarios in the proposed model. To create the stochastic file for representing demand uncertainty, we then need to assign probability to each of the demand values taken as stochastic input. For simplicity, we assign equal probability for each of the demand value taken as input to the GAMS file. When we employ Monte Carlo sampling on DECIS, it samples out all possible universe scenarios, sampled from the original probability distribution. This corresponding sample is then taken and solved using decomposition technique.

The mathematical model presented in this paper is coded on GAMS 24.1.3 and run by CPLEX 12.5.1.0 solver and DECIS solver respectively on an Intel (R) Core (TM) i7-3770 Dual Processor with 24GB RAM and a $3.40 \mathrm{GHz}$ CPU. The definition of the uncertain parameters, the input format and the output are obtained by DECIS solver. DECIS solver applies Benders decomposition/L-shaped method for solving large scale stochastic programming. The L-shaped method offers the advantage of special decomposable structure of the two stage stochastic programming model and is a widely applicable and popular method for solving stochastic programming [42], [43]. Benders decomposition/L-shaped method divides the original problems into a master problem and a sub-problem based on first and second stage variables and equations. Thus, this method offers an effective and efficient technique for solving large scale stochastic 
programming.

In sum, in the first step, we treat the model as a deterministic one by assigning discrete values of demand data in the model. In the next step, we model demand uncertainty by taking probability distribution of this random parameter. In brief, in the deterministic model, demand is regarded as deterministic values; on the other hand, randomness to demand parameter is used in the stochastic model we develop. The optimum objective function values for the stochastic model and deterministic model for the test instances are reported in Table IV. The change of cost for switching from deterministic to stochastic model is also presented in the following Table.

TABLE IV: COMPARISON OF TOTAL COST FOR STOCHATSIC AND DETERMINISTIC MODEL

\begin{tabular}{cccc}
\hline \hline \multirow{2}{*}{$\begin{array}{c}\text { \# of } \\
\text { scenarios }\end{array}$} & \multicolumn{2}{c}{ Total cost $(\$)$} & $\begin{array}{c}\text { Cost change } \\
(\%)\end{array}$ \\
\cline { 2 - 3 } & Stochastic model & $\begin{array}{c}\text { Deterministic } \\
\text { model }\end{array}$ & \\
\hline 2 & $65,267.8052$ & $77,235.931$ & -15.50 \\
3 & $83,649.277$ & $85,169.379$ & -1.78 \\
4 & $97,932.109$ & $91,317.775$ & 7.24 \\
5 & $1,10,504.805$ & $89,803.983$ & 23.05 \\
6 & $1,09,922.331$ & $1,08,693.896$ & 1.13 \\
7 & $1,23,424.419$ & $1,10,756.761$ & 11.43 \\
8 & $1,42,434.485$ & $1,25,478.519$ & 13.51 \\
9 & $1,49,868.598$ & $1,32,021.256$ & 13.51 \\
10 & $1,60,293.159$ & $1,38,775.712$ & 15.51 \\
11 & $1,66,561.810$ & $1,41,297.236$ & 17.88 \\
\hline \hline
\end{tabular}

The comparison of total cost variation for different test instances is given in Fig. 1. Fig. 1 depicts the effect of considering demand uncertainty in the proposed model.

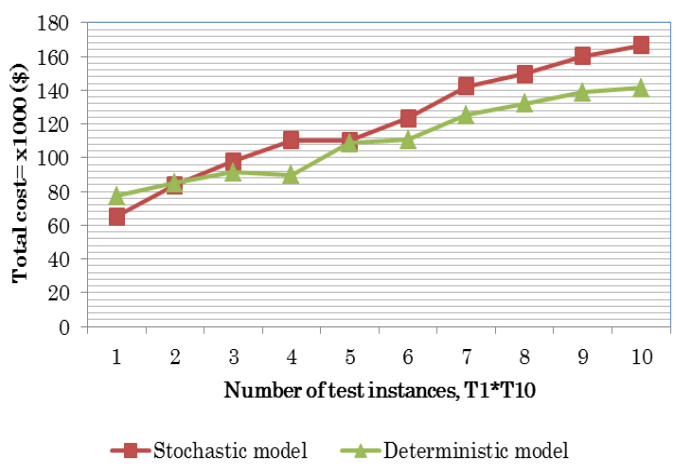

Fig. 1. Total cost variation for deterministic and stochastic model.

The results indicate that when the number of disruptions scenario increases, total cost for both model increases. However, we notice that the stochastic model demands higher cost than the deterministic model except for the first and second test case which contain two and three disruptions scenarios respectively. The reasons behind an increase of cost in stochastic model might be explained by the fact that when the number of disruption increases, the variation of demand increases and so it is hard for only the first decision to support all possible cases of such variable demand. So, it might require emergency order placement after a disruption happens and the uncertainty related to product demand reveals. Or, if the demand scenario is such that emergency order is not required; it calls for more order in the first stage thus increasing cost. In addition, it is observed that the change of total cost seems to become prominent when we consider more scenarios. More importantly, uncertainty does exist in a system in practice. Therefore, supply chain disruptions planning without considering uncertainty might lead to inaccurate and improper management decision grounded on a disruptions management strategies and activities. Thus, to make better decision in an uncertain environment, the stochastic model might outperform the deterministic model.

\section{CONCLUSION}

In this paper, a two stage stochastic programming approach is presented to formulate a quantitative supply chain disruptions planning framework. We consider demand and disruptions uncertainty and consider several disruptions scenarios to model a multi-product, multi-agent supply chain under disruptions risk. The model offers some important dimensions such as maximizing quality of incoming products and minimizing late deliveries apart from disruptions dealing cost. There might be several research issues that could be incorporated as an extension of the presented formulation. One could think of formulating and extending the model considering the budgets allocated to disruptions management in a financial year of an enterprise. Because, it is obvious that it involves cost for disruptions scenario planning and management. Therefore, considering financial restrictions uphold significant insights to any organization. The model might incorporate other cost parameters such as penalty cost and reward for violating or meeting quality/delivery performance, etc. However, one might think of exploring the model in a multi-period system.

\section{REFERENCES}

[1] K. B. Hendricks and V. R. Singhal, "An empirical analysis of the effect of supply chain disruptions on long-run stock price performance and equity risk of the firm," Prod. Oper. Manag., vol. 14, pp. 35-52, 2005.

[2] R. Handfield and K. P. McCormack, Supply Chain Risk Management: Minimizing Disruptions in Global Sourcing, 2007, p. 136.

[3] I. S. Papadakis, "Financial performance of supply chains after disruptions: an event study," Supply Chain Manag. An Int. J., vol. 11, pp. 25-33, 2006.

[4] T. Wu, J. Blackhurst, and P. O'grady, "Methodology for supply chain disruption analysis," Int. J. Prod. Res., vol. 45, pp. 1665-1682, 2007.

[5] C. S. Tang, "Perspectives in supply chain risk management," Int. J. Prod. Econ., vol. 103, no. 2, pp. 451-488, Oct. 2006.

[6] S. Chopra and M. S. Sodhi, "Managing risk to avoid supply-chain breakdown," MIT Sloan Manag. Rev., vol. 46, pp. 53-62, 2004.

[7] M. K. Agrawal and M. H. Pak, "Getting smart about supply chain management," McKinsey Q., vol. 10, no. 2, pp. 22-27, 2001.

[8] T. Murino, E. Romano, and L. C. Santillo, "Supply chain performance sustainability through resilience function," in Proc. 2011 Winter Simul. Conf. WSC, pp. 1600-1611, 2011.

[9] C. W. Craighead, J. Blackhurst, M. J. Rungtusanatham, and R. B Handfield, "The severity of supply chain disruptions: Design characteristics and mitigation capabilities," Decis. Sci., vol. 38, no. 1, pp. 131-156, 2007.

[10] C. W. Zobel and D. Cook, "A decision support framework to assess supply chain resilience," in Proc. the 5th International ISCRAM Conference, Washington, USA, 2008, May 2008, pp. 596-605.

[11] R. L. Dillon and J. B. Mazzola, "Management of disruption risk in global supply chains," IBM J. Res. Dev., vol. 54, pp. 1-9, 2010.

[12] C. A. A. MacKenzie, J. R. B. Santos, and K. A. Barker, "Measuring changes in international production from a disruption: Case study of the Japanese earthquake and tsunami," Int. J. Prod. Econ., vol. 138, pp. 293-302, 2012.

[13] P. L. Meena, S. P. Sarmah, and A. Sarkar, "Sourcing decisions under risks of catastrophic event disruptions," Transp. Res. E Logist. Transp. Rev., vol. 47, p. 1058, 2011 
[14] A. Oke and M. Gopalakrishnan, "Managing disruptions in supply chains: A case study of a retail supply chain," Int. J. Prod. Econ., vol. 118 , pp. 168-174, 2009.

[15] A. M. Knemeyer, W. Zinn, and C. Eroglu, "Proactive planning for catastrophic events in supply chains," J. Oper. Manag., vol. 27, pp. 141-153, 2009.

[16] H. Yu, A. Zeng, and L. Zhao, "Single or dual sourcing: decision-making in the presence of supply chain disruption risks," Omega, vol. 37, pp. 788-800, 2009.

[17] P. R. Kleindorfer and G. H. Saad, "Managing Disruption Risks in Supply Chains," vol. 14, no. 1, pp. 53-68, 2009.

[18] S. C. Ellis, R. M. Henry, and J. Shockley, "Buyer perceptions of supply disruption risk: A behavioral view and empirical assessment," J. Oper. Manag., vol. 28, pp. 34-46, 2010.

[19] K. Stecke and S. Kumar, "Sources of supply chain disruptions, factors that breed vulnerability, and mitigating strategies," J. Mark. Channels, vol. 16, pp. 193-226, 2009.

[20] B. Tomlin, "On the Value of Mitigation and Contingency Strategies for Managing Supply Chain Disruption Risks," Manage. Sci., vol. 52, no. 5, pp. 639-657, May 2006.

[21] M. Parlar and D. Perry, "Inventory models of future supply uncertainty with single and multiple suppliers," Nav. Res. Logist., vol. 43, pp. 191-210, 1996.

[22] S. Minner, "Multiple-Supplier inventory models in supply chain management: A review," Int. J. Prod. Econ., vol. 81-82, pp. 265-279, 2003.

[23] V. Argod and A. Gupta, "A stochastic optimization case study using ILOG CPLEX concert technology: Dual sourcing model for managing supply chain disruptions," Unpubl. White Pap., 2006.

[24] H. Davarzani, S. H. Zegordi, and A. Norrman, "Contingent management of supply chain disruption: effects of dual or triple sourcing," Sci. Iran., vol. 18, pp. 1517-1528, 2011.

[25] C. Chiang and W. C. Benton, "Sole sourcing versus dual sourcing under stochastic demands and lead times," Nav. Res. Logist., vol. 41 , pp. 609-624, 1994.

[26] P. Kelle and P. A. Miller, "Stockout risk and order splitting," Decis. Sci., vol. 71, pp. 407-415, 2001.

[27] P. N. C. Cooke. (2001). Tsunami, floods and dual sourcing: Whatever happened to risk management? JustAuto. [Online]. Available: http://www.just-auto.com/analysis/whatever-happened-to-risk-manag ement_id118152.aspx.

[28] G. Allon and J. A. Van Mieghem, "The Mexico-China sourcing game: Teaching global dual sourcing," INFORMS Trans. Educ., vol. 10, pp. 105-112, 2010.

[29] Z. Ben Yang, G. Aydın, V. Babich, and D. R. Beil, "Using a dual-sourcing option in the presence of asymmetric information about supplier reliability: competition vs. diversification," Manuf. Serv. Oper. Manag., vol. 14, pp. 202-217, 2012.

[30] S. P. Venkatesan and S. Kumanan, "Multi-Objective supply chain sourcing strategy design under risk using PSO and simulation," Int. J. Adv. Manuf. Technol., pp. 1-13, 2011.

[31] Y. Wang, W. Gilland, and B. Tomlin, "Mitigating supply risk: Dual sourcing or process improvement?" Manuf. Serv. Oper. Manag., vol. 12, pp. 489-510, 2009.

[32] Z. X. Z. Xiaoqiang and F. H. F. Huijiang, "Response to the supply chain disruptions with multiple sourcing," in Proc. 2009 IEEE Int. Conf. Autom. Logist., 2009.

[33] S. Moritz and R. Pibernik, "The optimal number of suppliers in the presence of volume discounts and diffrent compensation potentials-an analytical and numerical analysis," Eur. Bus. Sch. Res., no. working paper, 2008.

[34] A. Latour, "Trial by fire: A blaze in Albuquerque sets off major crisis for cellphone giants-Nokia handles supply shock with aplomb as Ericsson of Sweden gets burned-was SISU the difference?," Wall Str. J., pp. 1-6, 2001.

[35] Y. Park, P. Hong, and J. Jungbae, "Supply chain lessons from the catastrophic natural disaster in Japan," Bus. Horiz., vol. 56, no. 1, pp. 75-85, 2013.

[36] X. Chen and J. Zhang, "Production control and supplier selection under demand disruptions," J. Ind. Eng. Manag., vol. 3, pp. 421-446, 2010.
[37] L. D. L. Dong and W. M. W. Ming, "Coordinating supply chain with demand and price factor disruptions," in Proc. 2006 Int. Conf. Manag. Sci. Eng., 2006

[38] T. Xiao, X. Qi, and G. Yu, "Coordination of supply chain after demand disruptions when retailers compete," Int. J. Prod. Econ., vol. 109, p. 162,2007

[39] M. G. Ierapetritou and E. N. Pistikopoulos, "Batch plant design and operations under uncertainty," Ind. Eng. Chem. Res., no. 35, pp. 772-787, 1996.

[40] G. B. Dantzig and P. Wolfe, "The decomposition principle for linear programs," Oper. Res., vol. 8, no. 1, pp. 101-111, 1960.

[41] J. F. Benders, "Partitioning procedures for solving mixed-variables programming problems," Numer. Math., vol. 4, no. 1, pp. 238-252, Dec. 1962.

[42] V. Slyke and R. J. Wets, "L-Shaped linear programs with applications to optimal control and stochstic programming," SIAM J. Appl. Math., vol. 17 , pp. 638-663, 1969.

[43] J. R. Birge and F. Louveaux, Introduction to stochastic programming, New York: Springer, 1997.

[44] G. W. Dickson, "An analysis of vendor selection systems and decisions," J. Purch., vol. 2, pp. 5-17, 1966.

[45] M. M. Akarte, N. V Surendra, B. Ravi, and N. Rangaraj, "Web based casting supplier evaluation using analytical hierarchy process," J. Oper. Res. Soc., vol. 52, no. 5, pp. 511-522, May 2001.

[46] S. Cameron and D. Shipley, "A discretionary model of industrial buying," Manegerial Decis. Econ., vol. 6, pp. 102-111, 1985.

[47] L. Li and Z. B. Zabinsky, "Incorporating uncertainty into a supplier selection problem," Int. J. Prod. Econ., vol. 134, pp. 1-13, 2009.

[48] S. B. Petkov and C. D. Maranas, "The design of multiproduct batch plants under uncertainty with staged expansion," Comput. Chem. Eng. vol. 22, pp. 115-126, 1989.

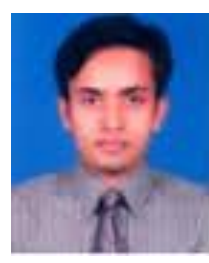

S. M. Ali was born at Narail, Bangladesh in 1983. The author has obtained both his bachelor of science and master of science degree in industrial and production engineering (IPE) from Bangladesh University of Engineering and Technology (BUET) in 2007 and 2009 respectively. His major field of study is the area of industrial engineering and management. Currently, he is a graduate student in the Department of Architecture, Civil Engineering and Industrial Management Engineering in Nagoya Institute of Technology, Nagoya, Japan. Previously he served as an assistant professor in the Department of Industrial and Production Engineering (IPE) in Bangladesh University of Engineering and Technology (BUET) Bangladesh. His research appears in International Journal of Production Research, Management Science Letters, International Journal of Operations and Quantitative Management, etc. His research interest includes supply chain disruptions management, business continuity planning and management and application of artificial intelligence in manufacturing and service planning and decision making.

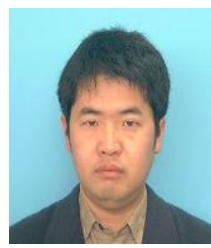

K. Nakade is from Japan. He is a member of the Operations Research Society Japan. He has received both his bachelor of science and master of science in engineering from Kyoto University, Kyoto, Japan in 1986 and 1988 respectively. And, He received a PhD from Nagoya Institute of Technology, Nagoya, Japan His research is focused in the area of operations research. Currently, he is a professor in the Department of Architecture, Civil Engineering and Industrial Management Engineering at Nagoya Institute of Technology, Japan. His research appears in European Journal of Operational Research, Computers and Industrial Engineering, International Journal of Productions Economics, etc. His research interest covers the analysis of stochastic models as queues, Markov processes, game theory, and inventory models and their applications to production systems and supply chains. 